http://jmscr.igmpublication.org/home/ ISSN (e)-2347-176x ISSN (p) 2455-0450

crossref DOI: https://dx.doi.org/10.18535/jmscr/v8i3.90

Journal Of Medical Science And Clinical Research

\title{
Management of cancer of the left colon in occlusion by colectomy in two stages at the CHU of Libreville
}

\author{
Authors \\ L S Bayonne Manou ${ }^{1 *}$, F K Diallo', K Dyatta Mayombo', C Ekogha Ekogha ${ }^{1}$, \\ J D Ondo ${ }^{1}$, B Nguema Asseko', B Mabika ${ }^{2}$, F Ondo Ndong ${ }^{1}$ \\ ${ }^{1}$ Department of Visceral Surgery of the University Hospital Center of Libreville \\ ${ }^{2}$ Laboratory of Histopathology of the Faculty of Medicine of Libreville \\ *Corresponding Author \\ Doctor Louis Stanislas Bayonne Manou \\ BP: 5258 Libreville, Gabon
}

\begin{abstract}
Goal: To report the epidemiological, diagnostic aspects and the results of the two-stage surgical management of cancer of the left colon in occlusion.

Patients and Method: It was a retrospective study carried out over 3 years at the Center Hospitalier Universitaire of Libreville (January 2017 and December 2019), on cancer of the left colon in occlusion having undergone a colectomy in two stages. The epidemiological and diagnostic parameters, the results of surgical exploration, the operative technique and the post-operative procedures have been described.

Results: Fifteen clinical files were retained including 9 men and 6 women. The average age was 52 years. Abdominal pain, cessation of materials and gas, and vomiting were the tell-tale signs. The abdomen without preparation showed hydroaeric levels $(n=11)$. Colonic lumen stenosis with segmental wall thickening was observed on abdominal computed tomography in all patients.

The surgical approach was a mid-xypho-pubic laparotomy. The seats were: sigmoid colon $(n=7)$; the colonic $(n=4)$ and descending colon $(n=4)$ angle. It was performed: 12 colectomies (Hartmann), one colectomy (Bouilly Voklmann) and two permanent colostomies.

The secondary locations were: hepatic metastases $(n=4)$, peritoneal carcinosis $(n=2)$. The histology was in favor of an adenocarcinoma $(n=13)$. Immediate morbidity was $20 \%$ and $13.4 \%$ respectively

Conclusion: Occluded left colon cancer is common. Patients are young. We are campaigning for a tumor resection and a temporary left colostomy followed by a restoration of continuity in a second step.

Keywords: colon cancer, occlusion, colectomy, colostomy.
\end{abstract}

\section{Introduction}

Colon cancer is a global problem with an annual incidence of around 1 million cases and a mortality of over $500,000^{[1]}$. In Europe, the disease occurs in $90 \%$ of cases in subjects over 50 years of age. However, it is not uncommon to find it in the youngest ${ }^{[2]}$. In Africa, the incidence is increasing because of changes in eating habits, lifestyle, acquisition of diagnostic means ${ }^{[3]}$. The late discovery, insufficient therapeutic means and its poor prognosis make it a serious condition. Bowel obstruction is one of the most common progressive complications of colon cancer ${ }^{[4]}$ Our objective is to report the epidemiological, 
diagnostic and the results of the colectomy in two stages in our professional environment.

\section{Patients and Method}

It was a retrospective and monocentric study carried out in our Department of Visceral Surgery, from January 2016 to December 2019. All patients undergoing surgery for cancer of the left colon in occlusion were included. Cancers of the rectum and right colon were excluded. Data from the clinical examination, abdomen without preparation, abdominal computed tomography and histological analysis of the operating room confirmed the diagnosis. The variables studied related to age, gender, clinic, results of surgical exploration, operative technique and immediate operative suites. The data collected on preestablished cards were analyzed on an Excel table and by comparison of the percentages and the means.

\section{Results}

During the study period, 15 patients underwent surgery for occluded left colon cancer. There were 9 men (60\%) and 6 women (40\%). The sex ratio was 1.5 . The average age was 52 (32-64). No history of family cancer or polyps was found.

Occlusion was progressive in 8 patients and abrupt in 7 patients. It was a frank occlusive syndrome with abdominal pain, stopping materials and gas exceeding 24 hours, vomiting and abdominal meteorism. He was found during the interrogation of transit disorders: chronic constipation (6 cases), alternating constipation and diarrhea ( 3 cases). There was also asthenia and dehydration in 3 patients. The blood test revealed anemia $(n=10)$, hyponatremia $(n=6)$. The dosage of creatinine, urea and blood sugar was done in all patients as part of the preoperative assessment. The abdomen without preparation (ASP) showed hydroaeric levels in favor of colonic occlusion in 11 cases. Abdominal computed tomography (CT) revealed segmental tumor-like colonic thickening and colon stenosis in all cases. All our patients were operated on in emergency within 12 hours after a short resuscitation

The surgical approach was a xypho-pubic laparotomy under general anesthesia. On exploration the colonic tumor was uni focal. The seats were: the sigmoid colon ( 7 cases), the left colic angle (4 cases) and the descending colon (4 cases). The secondary locations were 5 cases of liver metastases and 2 cases of peritoneal carcinosis. The surgical methods are illustrated in Table I

Table I. Surgical methods $(\mathrm{n}=15)$

\begin{tabular}{|l|c|c|}
\hline type of operation & number & percentage \\
\hline $\begin{array}{l}\text { Segmental colectomy } \\
\text { colostomy (Hartmann) }\end{array}$ & 7 & 46,7 \\
\hline $\begin{array}{l}\text { Hemicolectomy + colostomy } \\
\text { (Hartmann) }\end{array}$ & 5 & 33,3 \\
\hline Final left iliac colostomy & 2 & 13,3 \\
\hline $\begin{array}{l}\text { colectomy + double colostomy } \\
\text { (Bouilly Volkman) }\end{array}$ & 1 & 6,7 \\
\hline Total & 15 & 100 \\
\hline
\end{tabular}

The restoration of digestive continuity was achieved after 3 months in 8 patients, three cases were lost to follow-up. Liberkühnian adenocarcinoma was the dominant histological type with 13 cases. One case of leiomyosarcoma and one case of carcinoma were found. The TNM classification has been reported in 9 patients including: T2 (3 cases), T3 (4 cases) and T4 (2 cases). The morbidity was marked by: 2 cases of parietal suppuration and necrosis of the stoma. Two patients had died in the immediate postoperative period between the 1st and 7th day, one of them from hemorrhagic shock following an upper digestive hemorrhage and the second from multiple organ failure.

\section{Discussion}

Occlusion is one of the main complications that can occur during the development of colon or colorectal cancer. It is a formidable complication, the incidence of which is evaluated between 8 and $29 \%$ of $\mathrm{CRC}^{[5]}$.We have listed 27 colon cancers, including 15 of the left colon in occlusion, ie $55.6 \%$. This rate is underestimated due to the multifaceted difficulties linked to the management of carcinological pathology in certain structures in 
Libreville. This increase in the number of cases is certainly linked to the significant change in the eating habits of the population in Libreville. RAVELOSON et al in Madagascar reported a rate of $49 \%{ }^{[6]}$.

Contrary to certain data in the literature which describes it as cancer in the elderly ${ }^{[7]}$. In our series, the patients are young with an average age of 52 years. This age is superimposable on that found in the study of DIALLO et al in Gabon ${ }^{[3]}$. This observation accounts for the precocious onset of colon cancer in African populations. It suggests the existence of genetic and environmental factors, most often unknown, and the rarity of precancerous lesions is observed in many African studies including that of PEGHINI et al in Dakar ${ }^{[8]}$. The male predominance found is classic. This observation is consistent with African data ${ }^{[9]}$. In other studies, a predominance of women has been reported ${ }^{[3,10]}$. The sex ratio is 1.45 . It can be superimposed on that of the study by SAWADOGO A. et al in Burkina Faso which is $1.42^{[11]}$.

Clinically, the presence of intermittent abdominal pain with transit disorders, chronic constipation or alternating constipation with diarrhea are usually trivialized, rectal bleeding is attributed to hemorrhoidal disease, diarrhea considered as $d$ he infectious origin and the majority of patients often resort to self-medication or even to traditional medicine ${ }^{[12]}$. However, deterioration of the general state, abdominal pain, cessation of materials and gases and vomiting must attract the practitioner's attention and point towards an advanced form. These signs are reported by several African authors $^{[6,13]}$. The main two exams to confirm the diagnosis are the chest X-ray and abdominal CT The ASP is in everyday use easily accessible. It allows to confirm the occlusion clinically, to suspect it on the presence of hydroaeric levels. However, it presents limits for determining the tumor etiology, which makes it complemented by abdominal $\mathrm{CT}^{[14]}$. The abdominal CT scan is the benchmark for positive diagnosis and extension workup. It locates the tumor, detects possible secondary locations and guides the operating technique as pointed out by Delabrousse ${ }^{[15]}$.

Surgery is the only method capable of curing colon cancer. It remains the basis of therapeutic care. The first approach is a xypho-pubic laparotomy, it is unanimously accepted by African authors practicing south of the Sahara ${ }^{[11,13]}$. During the operation, it is important to explore the entire digestive tract so as not to miss another location. Currently in the West, the laparoscopic approach is more and more practiced. It has advantages in terms of aesthetics, reduction of post-operative pain and hospital stay ${ }^{[16]}$. We do not have experience with this technique.

Regarding the left colic locations, the surgical approach must take into account the patient's condition, the location of the tumor, the degree of locoregional involvement, the surgeon's expertise and the resources available. There is still an important controversy because several methods have been described: intervention in a single step, in two steps or in three steps ${ }^{[17]}$.

An initial colostomy from near upstream allows the emergency lifting of the occlusion and exploration of the abdominal cavity by a quick and simple intervention, carcinological tumor excision surgery is performed 8 to 15 days later. The upstream colostomy is the attitude recommended by the French consensus conference on the treatment of colon cancer ${ }^{[18]}$. This method we did not perform during our study period. Segmental colonic resection with restoration of immediate continuity without preparation. This technique is practiced by other surgical teams in Africa such as that of Thiès in Senegal ${ }^{[19]}$. The complication of this method is the anastomotic fistula which can be reduced by colonic preparation on the operating table. Peroperative washing involves a risk of septic soiling, lengthens the operating time and increases morbidity and mortality ${ }^{[20]}$. Taking into account all these elements and the observation in operative of a significant tumor dilation with sometimes a fragile infiltrated colic wall and especially of the professional context in which the patients are 
taken care of urgently in our environment, we prefer an intervention to two time. An immediate colectomy without immediate restoration of digestive continuity (intervention by Hartmann or Bouilly Volkmann) was performed as an emergency after a colon cancer resection. The advantages are: the removal of the obstacle, the eradication of sepsis and the analysis of the operating room. The disadvantage of this technique is the management of colostomy bags on an outpatient basis ${ }^{[21]}$. A rate of $60 \%$ of patients keep their colostomy not because of the technical impossibility but for reasons related to the patient's terrain ${ }^{[22]}$.

The restoration of continuity is often planned after the adjuvant chemotherapy treatment. This delay in restoring digestive continuity is at the discretion of the surgeon and the patient's condition. In our context it is decided beyond the $3 \mathrm{rd}$ month. Eight patients had a restoration of digestive continuity. In the literature, the time varies from 10 to 365 days $^{[22]}$. In tropical environments, digestive anastomoses are performed manually.

Currently, in the West, the placement of a colonic stent can be proposed. The stent can even be the definitive instrumental treatment in a palliative situation. It can lift the occlusion, avoid emergency surgery, improve both the state of the colonic wall and the general condition of the patient. Resection-anastomosis can then be considered after a more or less long delay compared to the occlusive episode ${ }^{[23]}$. Lieberkühnian adenocarcinoma is the dominant histological type with well-differentiated and highly malignant cells leading to a poor prognosis. This observation is similar to the study by NDAH et $\mathrm{al}^{[24]}$.

\section{Conclusion}

Our study, although limited, a retrospective study, allowed us to expose a technique on the surgical management of occlusions in cancer of the left colon. Our preference is in favor of a tumor resection and colostomy followed in a second step by a restoration of digestive continuity.

\section{Acknowledgments}

We thank the health staff of the visceral surgery service for the production of this article and the patients who have given their consent to the processing of their medical records.

\section{No conflict of interest}

\section{References}

1. Parkin, D.M, Bray F, Ferlay J. Global cancer statistics 2002 CA Cancer J Clin, 2005; 55(2): 74-108.

2. Bernier A, Simard M. Le traitement du cancer colorectal métastatique Partie 1. Pharmactuel. 2007 ; (40) :138-47.

3. Diallo Owono FK, Nguema Mvé R, Ibaba J, Mihindou C, Ondo Ndong F. Aspects épidémiologiques et diagnostiques des cancers colorectaux à Libreville (Gabon). Med. Trop. 2011 ; (71) : 605-07.

4. Konate I, Cisse M, Diallo Owono FK, et al . L a prise en charge des cancers colorectaux en occlusion à la clinique chirurgicale le Dantec à Dakar (Sénégal) . Bull Med Owendo 2009 ; $12: 31-3$.

5. Manfredi S, Sabbagh G, Vanbiervliet T. Place des prothèses coliques dans la stratégie thérapeutique du cancer colorectal. Acta Endosc 2014;44:208-218.

6. Raveloson J R, Rantomalala $\mathrm{H}$ Y $\mathrm{H}$, Rakotoarisoa $\mathrm{B}$ et al. Prise en charge des cancers $\mathrm{du}$ colon en occlusion au centre hospitalier de Soavinandriana. Med d'Afr Noire 2005 ; 52 :633-37.

7. Lannes Dominique. Assurer les cancers gastrique et colorectal en 2012. SCOR INFORM 2012 ; 3-6.

8. Peghini M, Barabe $\mathrm{P}$, Touze Je et al . Epidémiologie des cancers du tube digestif au Sénégal: apport de 18000 endoscopies effectuées à l'Hôpital Principal de Dakar. Médecine tropicale 1990;50:205-8.

9. Ele N, Okiemy G, Lebeau R et al .Le cancer $\mathrm{du}$ colon gauche au CHU de Brazzaville. 
Résultats du traitement chirurgical. Mali Médical 2006 ; 21 :1-3.

10. Raherinantenaina F, Rjaonarivony $\mathrm{T}$, Rakotomena D.S, Rajaonanahary T.M.A, Rakoto-Ratsimba.Evaluation des modalités diagnostiques et thérapeutiques des cancers colorectaux pris en charge dans le centre hospitalier universitaire à Antananarivo. Med. Afr. Noire. 2013 ; 60 (6) : 269-78.

11. Sawadogo A, Ilboudo PD, Durand G, Peghini M, Branquet D, Sawadogo AB. Epidémiologie des cancers du tube digestif au Burkina Faso: apport de 8000 endoscopies effectuées au centre hospitalier national SANOU SOURO (CHNSS) de BOBO DIOULASSO. Méd.Afr. Noire $2000 ; 47(7)$ : 342-5.

12. Diémé Eugène GP Amaye, Tine Marie Monique Codou, Sall Ibrahima et al . Prise en charge des cancers colorectaux en occlusion a l'hopital principal de Dakar a propos de 37 cas. Mali Medical $2019 ; 34$ : 40-7

13. Diallo Owono F K, Nguema Mvé R, Mihindou Boussougou $\mathrm{C}$ et al. Prise en charge thérapeutique des cancers colorectaux à Libreville. Rev .Afr.Chir.Spec $2011 ; 1$ :18-23

14. Jackson P G, Raiji M. Evaluation and management of intestinal obstruction Am Fam Physician 2011;83(2):159-165.

15. Delabrousse E, Saguet O, Destrumelle N et al. Volvulus du sigmoïde : intérêt et apports de l'étude scanographique. J Radiol 2001 ; 82 :930-32.

16. Lacy AM, Garcia -Valdecasas J C, Delgado S et al. Laparoscopie -assisted colectomy for treatement of non metastatic colon cancer: a randomized trial .Lancet $2002 ; 359$ :2224-29.

17. Van Gijn W, van den den Broek CB, Mroczkowski P. The EURECCA projet : Data items scored by European colorectal cancer audit registries. Eur J Surg Oncol 2012; 38:467-71.
18. Adoubi I, Kouadio KG, M' bra $\mathrm{K}$ et al. Chimiothérapie des cancers du rectum localement avancés .Mali Med 2006 ; 21 : 1-4.

19. Pa Ba, TMM Wade, Diop B et al .Traitement en urgence des cancers du colon en occlusion a l'hôpital de Thiès, Sénégal .J Afr Chr Digest 2017 ; 17 :2223-7.

20. Gainant A, Emergency management of acute colonic cancer obstruction. J Visc Surg $2012 ; 149: 3-10$.

21. Millat B . traitement des cancers coliques en occlusion Ann Chir 2003 ; 128:349-35

22. Kouadio G K, Turquin T H. Cancers coliques en occlusion en Côte d'Ivoire .Ann Chir 2003 ; 123 :364-67.

23. Mackay CD, Craig W, Hussey JK, et al. Selfexpanding metallic stents for large bowel obstruction. Br J Surg 2011;98:1625-9.

24. Ndah K J, Doukouré B, Troh E et al .Epidémiologie et anatomo-pathologie des cancers colorectaux en Côte d'Ivoire. Carcinol Prat Afrique $2010 ; 9$ :50-7. 